\title{
Assessing the Future Trends of Reactive Power Demand of Distribution Networks
}

DOI:

10.1109/TPWRS.2017.2665562

\section{Document Version}

Accepted author manuscript

Link to publication record in Manchester Research Explorer

\section{Citation for published version (APA):}

Kaloudas, C., Ochoa, L., Marshall, B., Majithia, S., \& Fletcher, I. (2017). Assessing the Future Trends of Reactive Power Demand of Distribution Networks. IEEE Transactions on Power Systems, PP(99).

https://doi.org/10.1109/TPWRS.2017.2665562

\section{Published in:}

IEEE Transactions on Power Systems

\section{Citing this paper}

Please note that where the full-text provided on Manchester Research Explorer is the Author Accepted Manuscript or Proof version this may differ from the final Published version. If citing, it is advised that you check and use the publisher's definitive version.

\section{General rights}

Copyright and moral rights for the publications made accessible in the Research Explorer are retained by the authors and/or other copyright owners and it is a condition of accessing publications that users recognise and abide by the legal requirements associated with these rights.

\section{Takedown policy}

If you believe that this document breaches copyright please refer to the University of Manchester's Takedown Procedures [http://man.ac.uk/04Y6Bo] or contact uml.scholarlycommunications@manchester.ac.uk providing relevant details, so we can investigate your claim.

\section{OPEN ACCESS}




\title{
Assessing the Future Trends of Reactive Power Demand of Distribution Networks
}

\author{
Christos G. Kaloudas, Member, IEEE, Luis F. Ochoa, Senior Member, IEEE, Ben Marshall, \\ Shanti Majithia, Ian Fletcher
}

\begin{abstract}
In the last decade, the Transmission System Operator (TSO) in Great Britain has seen an acute declining trend of reactive power demand during periods of minimum load. Reactive power traditionally being absorbed by distribution networks is now in many cases injected to transmission. This not only results in significant voltage regulation challenges to the TSO but may also trigger future requirements for Distribution Network Operators (DNOs) to manage these reactive power exchanges. Nonetheless, for the TSO and DNOs to adopt suitable investment strategies, it is crucial to first quantify the extent of this decline in the near future. This work proposes a methodology to identify trends of reactive power demand using historical DNO monitoring and network data. Multiple scenarios are also considered to cater for potential changes in demand, generation and networks. The methodology is demonstrated on real British distribution networks, from the transmission-distribution interface to primary substations. The assessment reveals the significant effect of demand trends in primary substations on the overall transmission-distribution exchanges. It was also found that the potential use of shunt reactors in distribution networks would require significant investment, highlighting the importance of understanding reactive demand trends in planning costeffective solutions.
\end{abstract}

Index Terms-Demand trends, distribution networks, reactive power demand.

\section{INTRODUCTION}

$\mathrm{V}$ OLTAGE rise excursions in transmission networks during normal operation are, in general, related to the design of the assets (lines, transformers, etc.), the variability of the power flows (demand/generation interactions), and low levels of reactive power demand, all particularly during periods of minimum load. While in most countries these factors are well understood and therefore corrective actions are planned accordingly, the fast pace in which distribution networks are evolving (less inductive loads, distributed generation, extensive use of underground cables) is already posing challenges to some of them.

This work has partly been funded by National Grid and the six Distribution Network Operators in Great Britain (ENWL, NPowergrid, SPEN, SSE, UKPN, WPD) through the "Reactive Power Exchange Assessment and Characterisation (REACT)" Project.

C. G. Kaloudas is with Electricity North West Limited (ENWL), UK. L. F. Ochoa is with The University of Melbourne, Parkville, VIC 3010, Australia and with The University of Manchester, Manchester M13 9PL, UK. B. Marshall is with National Grid, UK. Shanti Majithia is with Energy \& Climate Advisory Services, UK. I. Fletcher is with Northern Powergrid, UK. (e-mails: christos.kaloudas@enwl.co.uk, luis_ochoa@ieee.org)
From 2011 to 2012, National Grid, the Transmission System Operator (TSO) in Great Britain, reported 165 voltage rise excursions in the $400 \mathrm{kV}$ network [1]. This number is significant compared to the only 1 reported from 2007 to 2010. Although corrective actions, including the use of shunt reactors and contracting generation for reactive power absorption, have successfully minimized excursions so far, there is a need to understand the main factors and their trends so future investments can be scheduled accordingly [2].

The increased voltage levels in transmission are considered to derive mainly from the declining reactive power $(\mathrm{Q})$ demand of distribution networks during periods of minimum load. Increasingly less inductive distribution networks are absorbing less reactive power from transmission, or even exporting. For instance, from 2005 to 2014 Q demand during minimum load in Great Britain reduced from 7.5 to $2.1 \mathrm{Gvar}$ [3]. This and similar trends not only result in significant voltage regulation challenges to the TSO but may in future also trigger a requirement for Distribution Network Operators (DNOs) to manage these reactive power exchanges. For instance, the European Demand Connection Code (EDCC) [4] suggests that no var exports will be allowed towards transmission when demand is below $25 \%$ of maximum demand supplied. Nonetheless, for the TSO and DNOs to adopt suitable investment strategies, it is crucial to first quantify the extent of this decline in the short and long terms.

Most of the work in this area focuses on the operational and market perspectives (e.g., control of distribution voltages [5][6], provision of services from distribution to transmission [7], [8]). There is very limited documentation investigating the decline in reactive power demand of distribution networks, i.e., at the transmission-distribution (T-D) interfaces.

This work proposes a methodology to identify future trends of reactive power demand using historical DNO monitoring and network data. Crucially, multiple scenarios are considered to cater for potential changes in demand, generation and networks. The methodology was developed within the REACT project which started in 2013 and involved the TSO and the 6 DNOs in Great Britain [9]. Its application is demonstrated in detail on a real, large distribution network in the North East of England, modelled from the T-D interface (e.g., 275/132 kV) to primary substations (e.g., $33 / 11 \mathrm{kV}$ ).

This paper is structured as follows: To illustrate the extent of the Q demand problem that might be found in other DNOs around the world, section II presents the historical decline trends during periods of minimum load across all six DNOs in 
Great Britain. The proposed methodology to assess future Q demand at T-D interfaces, which consists of four stages, using real distribution networks and monitoring data is described in section III. The methodology for each of these stages is described in section IV. The corresponding application and scenario-based assessment of future Q demand are demonstrated in sections V and VI, respectively, using the top 10 critical T-D interfaces per UK DNO. The cost of shunt reactors, as a potential solution is also estimated in section VII. Finally, solutions with existing assets are discussed in section VIII and conclusions are drawn in section IX.

\section{HistoricAL TRENDS IN GREAT BRITAIN}

The assessment of the $\mathrm{Q} / \mathrm{P}$ ratios of the overall demand at the T-D interfaces is a traditional approach followed by transmission operators to understand trends in $\mathrm{Q}$ demand during periods of minimum load [3], [10]. However, there is limited literature that investigates the corresponding trends.

In [8], all the 336 T-D interfaces across Great Britain, also known as Grid Supply Points (GSPs), were studied from 2005 to 2012. Despite the use of yearly data, it was found that Q demand during minimum load reduced across all DNOs, i.e., UK Power Networks (UKPN), Electricity North West Limited (ENWL), Northern Powergrid (NP), Western Power Distribution (WPD), Scottish Power (SP), and Scottish and Southern Energy (SSE). To further investigate this issue, this work proposed metrics based on the declining $\mathrm{Q} / \mathrm{P}$ ratios during minimum load from 2005 to 2012, Q/P ratios in 2012, and peak demand in 2012. A total of 60 GSPs (10 per DNO) were identified as critical. Although these GSPs correspond to the most severe cases, they correspond to almost $20 \%$ of the GSPs in Great Britain and are located across all DNO regions.

Using half-hourly data from 2009 to 2013, Fig. 1 shows the daily $\mathrm{Q} / \mathrm{P}$ ratios from May to July during minimum load for the critical GSPs identified in [8]. Approximations using linear regression analysis are also depicted, showing declining trends in $\mathrm{Q} / \mathrm{P}$ ratios across all DNOs. It is noteworthy that capacitive Q/P ratios during minimum load (i.e., var exports to transmission) can be found in the most recent years (2012 and 2013) for all DNOs. These results clearly show that increasingly more reactive power is being exported from distribution networks, thus potentially requiring additional voltage management actions from the transmission operator. Consequently, it is critical to understand the key parameters affecting the demand of distribution networks.

\section{Assessment OF Future TRENDS: OVERVIEW}

Transmission operators traditionally produce future trends of $\mathrm{Q}$ demand without modeling distribution networks. Nonetheless, the interactions between network and demand changes in evolving distribution networks need to be captured for a more accurate quantification. Thus, this work proposes a methodology to assess future $\mathrm{Q}$ demand at T-D interfaces during periods of minimum load using both historical DNO monitoring data as well as network models.

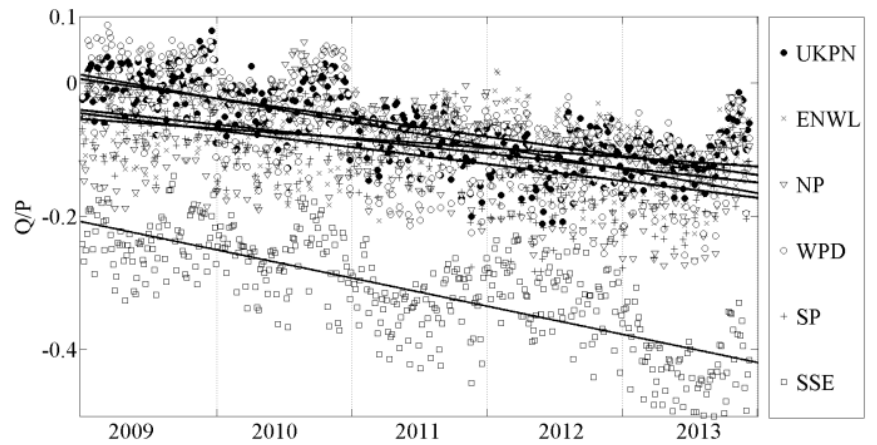

Fig. 1. Daily $\mathrm{Q} / \mathrm{P}$ ratio during minimum $\mathrm{P}$ for the aggregated demand of top 10 critical GSPs per DNO in Great Britain

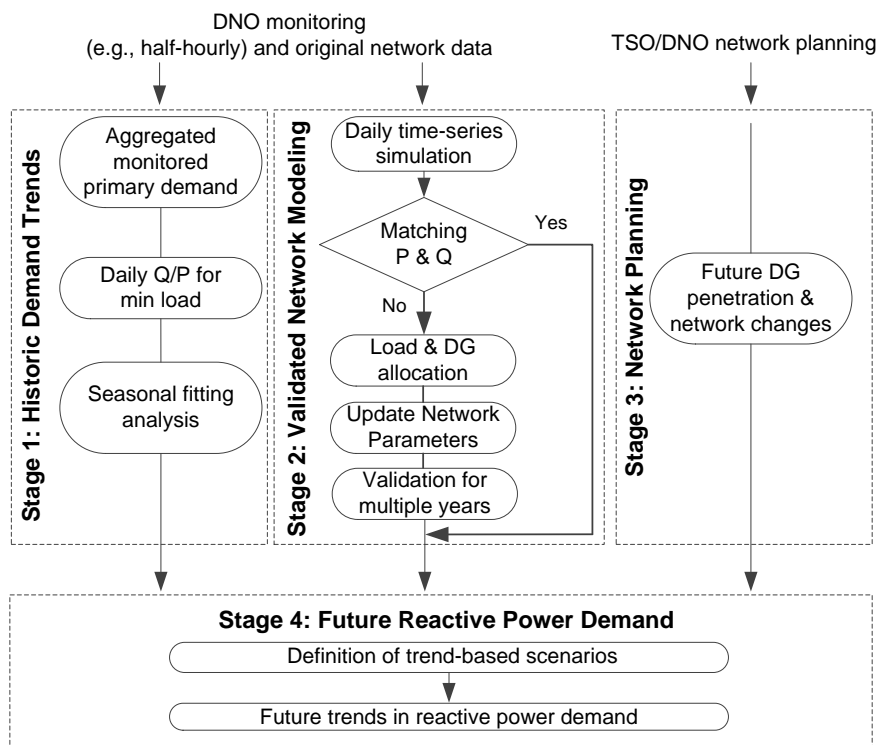

Fig. 2. The proposed methodology to assess future Q demand at transmissiondistribution interfaces during periods of minimum load.

The proposed methodology consists of 4 stages as illustrated in Fig. 2. In Stage 1, historical monitoring data of primary substations (typically the last point of monitoring) is used to obtain daily $\mathrm{Q} / \mathrm{P}$ ratios during minimum load for each of the available (recent) years. Trends are then identified considering particularly those months experiencing the lowest Q/P ratios. In Stage 2, network and monitoring data is used to produce validated network models. Models produced by DNOs are typically used for peak demand studies and therefore, in some cases, accurate line and cable susceptance values -necessary for the assessment of Q demand- might not be of importance. Thus, validated network models are needed to mimic the actual behavior of T-D interfaces in time-series power flow simulations during periods of minimum load. In Stage 3, TSO and DNO network planning information about scheduled network changes and distributed generation (DG) growth is gathered to be considered in the Stage 4 analysis. Finally, for a given horizon, the assessment of future Q demand during minimum load at the T-D interfaces is carried out in Stage 4 using multiple scenarios based on trends that also cater for national/regional policies.

\section{Methodology}

This section describes in detail the four stages of the 
proposed methodology to assess future $\mathrm{Q}$ demand. It is important to highlight that as availability and quality of network and monitoring data vary from DNO to DNO, some implementation aspects of the proposed methodology will also depend on the particular case (as shown in section V).

\section{A. Stage 1: Historical Demand Trends}

Primary substations have traditionally been important points for the real-time monitoring of demand in distribution networks, and hence of time-series historical data (although stored with longer sampling intervals). This data is crucial in the proposed methodology as it allows validating upstream network models and capturing the aggregated demand behavior for downstream primary substations, i.e., residential, commercial and industrial loads, DG, and network changes.

To extract the historical demand trend for a given T-D interface, in Stage 1, the daily Q/P ratios of the corresponding aggregated primary demand (obtained from historic $\mathrm{P}$ and $\mathrm{Q}$ monitoring data) are calculated. Once these trends are identified using a fitting approximation (e.g., linear, exponential) for critical periods (e.g., critical months), they can be used by Stage 4 .

\section{B. Stage 2: Validated Network Modelling}

Network assets, in particular lines, absorb or inject reactive power according to the power flows and voltages they are exposed to. This relationship can be described considering the $\mathrm{Q}$ demand of the an overhead line, $Q_{\text {line }}$, using (1) where $V_{l}$ and $V_{2}$ are the voltage magnitudes at the sending and receiving ends ( $\mathrm{Pi}$ equivalent), respectively, $B$ is the susceptance, $X$ is the reactance, and $I$ is the current magnitude through the line.

$$
Q_{\text {line }}=I^{2} \cdot X-\left(\frac{V_{1}^{2} \cdot B}{2}+\frac{V_{2}^{2} \cdot B}{2}\right)
$$

During periods of minimum demand, the $\mathrm{Q}$ absorption from the first term (smaller losses due to lower demand) is exceeded by the $\mathrm{Q}$ injection of the second term (voltages are higher due to lower demand), thus resulting in negative $Q_{\text {line }}$, i.e., Q gains. For the same line, this effect is further accentuated in higher voltage levels as the $\mathrm{Q}$ injection is proportional to the square of the voltage. Consequently, to adequately assess the extent of $\mathrm{Q}$ gains, network assets need to be adequately modelled.

In practice, however, network studies carried out by DNOs traditionally focus on periods of peak demand. Hence, network data, such as line susceptances, are not typically considered as critical parameters (e.g., to assess voltage drops). Moreover, in terms of monitoring data, not all intermediate or primary substations have $\mathrm{P}$ and $\mathrm{Q}$ demand available (e.g., only MVA data available, no monitoring devices, erroneous data, confidentiality issues).

In this context, Stage 2 proposes the production of validated network models by first allocating the load and DG profiles considering the available monitoring and currentlyused network data. Then, the line susceptances are updated to match the $\mathrm{Q}$ demand at the T-D interface. This process is explained in the following 4 steps.

- Step 1: Perform daily time-series power flow simulations using the available DNO network and monitoring data (e.g., half-hourly). Identify the mismatch in $\mathrm{P}$ profiles $\left(P_{\text {mismatch }}\right)$ between simulations and monitoring data at the T-D interface and intermediate substations.

- Step 2: Minimize the $P_{\text {mismatch }}$ by allocating $\mathrm{P}$ profiles for loads and DG. Adopt a proportional approach that considers the rating of the corresponding intermediate and/or primary substations. More specifically, the $k$-th load and $m$-th DG profiles without available monitoring data can be allocated taking into account the $P_{\text {mismatch }}$ at the substations operating upstream using the following equations:

$$
\begin{gathered}
P_{D G, m}=\frac{-S_{D G, m}}{\sum_{i=1}^{n} S_{\text {load }, i}} \cdot P_{\text {mismatch }} \\
P_{\text {load }, k}=\frac{S_{\text {load }, k}\left(1+\frac{\sum_{i=1}^{n} S_{D G, m}}{\sum_{i=1}^{n} S_{\text {load }, i}}\right)}{\sum_{i=1}^{n} S_{\text {load }, i}} \cdot P_{\text {mismatch }}
\end{gathered}
$$

where $S_{\text {load }}, S_{D G}$ are the nominal capacities in MVA for load and DG substations, respectively. The Q profiles for the load substations are produced adopting the average power factor of the neighboring/similar ones. For DG profiles, in cases where reactive power capabilities exist and are used, the corresponding reactive power profiles should be created (from measurements or derived from active power profiles).

It should be noted that generation profiles of large DG units connected upstream primary substations are usually available to DNOs. Nonetheless, even in cases without DG monitoring data, (2) can still serve the purposes of assessing the trends of reactive power. Indeed, although the allocated DG profiles in the presence of multiple sites and technologies are likely to be inaccurate on their own, in the aggregate they will still be a valid approximation as seen by networks upstream primaries.

- Step 3: Match Q profiles at the T-D interface by updating line susceptances across all voltage levels. In networks where the total length of overhead lines is expected to be larger than that of cables, this is achieved iteratively starting from the assumption that all lines are overhead and then different cable penetrations are adopted progressively. For instance, a $10 \%$ cable penetration means that all lines have a cable susceptance (generic for the voltage level) for $10 \%$ of its length. The remaining $90 \%$ corresponds to an overhead line. In cable dominated networks a similar iterative process can be carried out starting from the assumption of $100 \%$ cables.

- Step 4: To confirm the adequacy of the updated line susceptances repeat steps 1 and 2 for different days/seasons. If $\mathrm{Q}$ mismatches exist, then it is likely that other elements are influencing the $\mathrm{Q}$ demand (e.g., automatic capacitor banks) and therefore they should be accounted for.

\section{Stage 3: Network Planning}

Scheduled network changes as well as increased DG penetration can affect the future overall $\mathrm{Q}$ demand of distribution networks and therefore should be considered to 
assess the future $\mathrm{Q}$ demand during minimum load. Particularly for DG units, the local practice in terms of power factors should also be accounted for. Thus, in Stage 3 network planning information from TSOs and DNOs is taken into account respecting also regional characteristics (that might not follow national trends).

Network changes that can potentially affect Q demand are those that lead to $Q$ gains during minimum load or inject vars. This includes installation of new underground cables, the replacement of overhead lines with cables, and the installation of capacitor banks. DG, on the other hand, can produce power flows below the natural loading of distribution lines and, hence, lead to $\mathrm{Q}$ gains. Thus, the more relevant $\mathrm{DG}$ technologies to the region should also be considered (e.g., wind power or photovoltaic systems). Once the planning information is processed, the trends are embedded in Stage 4.

\section{Stage 4: Future Reactive Power Demand}

The ultimate outcome of the proposed methodology is produced in Stage 4 where, for a given horizon, the future Q demand during minimum load at T-D interfaces is assessed using different scenarios. Similarly to those adopted by the European Network of TSOs for Electricity (ENTSO-E) [4] and the TSO in Great Britain [11], Stage 4 scenarios should capture uncertainties that might affect demand, such as efficiency and low carbon policies.

Following the review of current approaches [11], [15], five trend-based scenarios are proposed and described as follows:

1. Existing Trends: This is the business as usual scenario. The identified historic trends at primary substations during minimum load, both in terms of $\mathrm{Q} / \mathrm{P}$ ratio and $\mathrm{P}$ demand, continue. Planned network changes as well as expected DG penetration are also considered using the available DNO and TSO network planning information (Stage 3).

2. Go Green: Renewable generation policies are taken into account in this scenario. It is different from the Existing Trends in that it considers a much higher DG penetration.

3. Effective Loads: Power factor and efficiency improvement measures from the demand side are considered in this scenario. This scenario modifies the Existing Trends by adopting a more acute decline for the $\mathrm{Q} / \mathrm{P}$ ratio and a reduction in $\mathrm{P}$ demand during minimum load.

4. Slow Progression: This is the most optimistic scenario. The identified historic trends at primary substations, Q/P ratio and $\mathrm{P}$ demand, as well as the expected DG penetration are all considered to be less acute.

5. Fast Progression: This is the most pessimistic scenario. It considers $\mathrm{Q} / \mathrm{P}$ ratio, $\mathrm{P}$ demand and $\mathrm{DG}$ penetration trends to be even more acute than the Existing Trends scenario. Furthermore, it also considers significant network changes such as high penetration of cables.

Although the above scenarios cover a realistic mix of factors influencing the future $\mathrm{Q}$ demand during minimum load, the spectrum of results will depend on the numerical assumptions and on the specific characteristics of the networks downstream the T-D interfaces under study.

\section{GReat Britain CASe Study - Stages 1-3}

Stages 1 to 3 of the proposed methodology are demonstrated in this section using real distribution network and monitoring data from multiple DNOs in Great Britain.

First, historical demand trends are identified (Stage 1) using DNO monitoring data from two large networks in the North West (ENWL) and South of England (UKPN). The process to produce validated network models (Stage 2) is then demonstrated with a large network in the North East of England (NP). Available network planning information from the UK TSO about future photovoltaic (PV) penetrations, across the country is also considered as part of Stage 3 . Finally, the effects on $\mathrm{Q}$ demand during minimum load from cable and PV penetrations as well as demand trends are quantified to illustrate the corresponding impacts.

\section{A. Stage 1: Historical Primary Demand Trends}

Aggregated half-hourly P and Q monitoring data from 2009 to 2014 corresponding to 33 and 18 primary substations from the ENWL and UKPN GSPs (T-D interfaces), respectively, is used in this analysis. First, daily $\mathrm{Q} / \mathrm{P}$ ratios during minimum $\mathrm{P}$ are calculated considering days of low demand (May to July). Fig. 3 and Fig. 4 show the corresponding behavior of the analyzed GSPs. It can be seen that the UKPN GSP (812MW of peak demand in 2013, London area) has a more acute decline in the Q/P ratio than the ENWL GSP (561MW).

To extract the $\mathrm{Q} / \mathrm{P}$ ratio trends four different fitting approximations, i.e., linear, quadratic, cubic and exponential, are considered using the Matlab software [16]. More specifically, the linear least squares method is used for the linear approximation, whereas the non-linear least squares method (i.e., iterative process involving the trust-region and Levenberg Marquardt algorithms) is used for the others. The resulting curves and the corresponding residual errors for the daily Q/P ratio are also presented in Fig. 3 and Fig. 4. It is evident for both GSPs that all fittings are almost linear. For the ENWL GSP, the rms errors for the linear and exponential approximations are 0.0424 and 0.0423 , respectively, i.e., a difference of $0.24 \%$. A small difference is also found for the UKPN GSP where the corresponding rms errors are 0.0187 and 0.0192 , i.e., a difference of $2.6 \%$. This is also supported by similar findings when analyzing other GSPs, including trends in minimum $\mathrm{P}$ demand [12]. Consequently, a linear approximation can be considered adequate to define historic primary demand trends in Britain.

Considering the linear approximation, the annual decline of the $\mathrm{Q} / \mathrm{P}$ ratio during minimum $\mathrm{P}$ is $5.9 \%$ for the ENWL GSP and $7.1 \%$ for the UKPN GSP. In terms of the minimum P demand, an annual decline was also found in both GSPs. The corresponding figures are 1.1 and $2.6 \%$, respectively.

\section{B. Stage 2: Validated Network Modelling}

The system under study is a large distribution network fed 

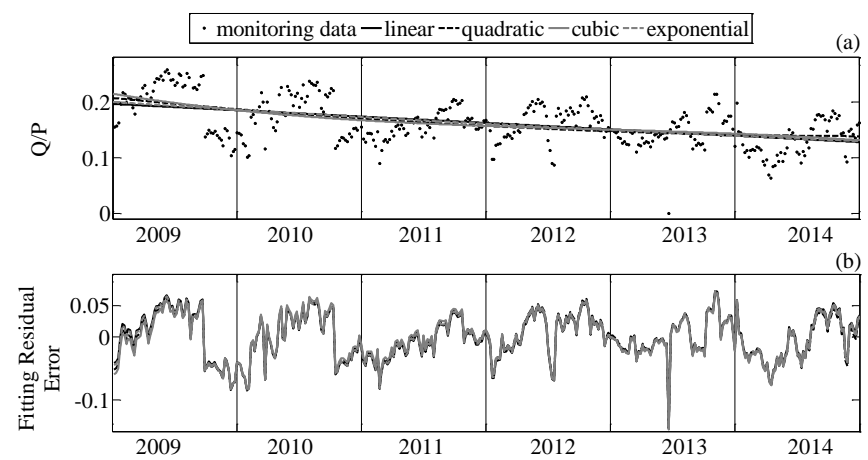

Fig. 3. Approximations of daily $\mathrm{Q} / \mathrm{P}$ ratios of the aggregated primary demand during minimum $P$ in a North England GSP (ENWL).
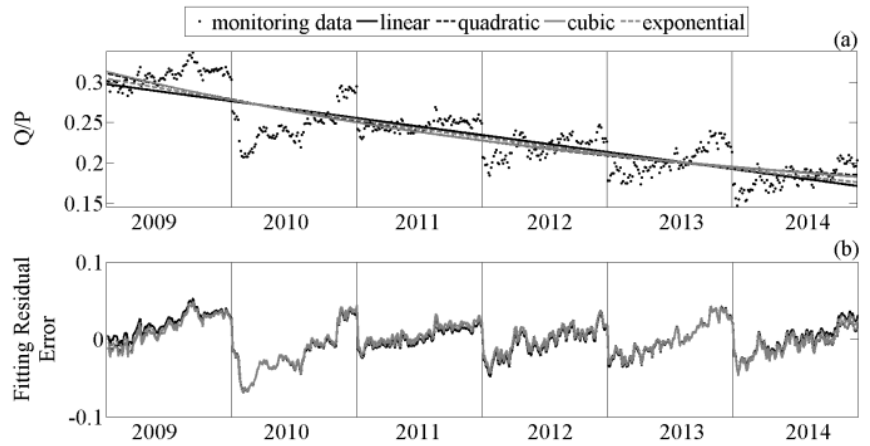

Fig. 4. Approximations of daily $\mathrm{Q} / \mathrm{P}$ ratios of the aggregated primary demand during minimum $\mathrm{P}$ in a London area GSP (UKPN).

by a critical GSP [8] operated by NP in the North East of England. Fig. 5 illustrates the different Bulk Supply Point (BSP) and primary substations fed by this GSP (with demands ranging from 120 to $460 \mathrm{MW}$ in 2013) as well as the corresponding monitoring points. Tables I and II summarizes the corresponding nominal voltages and ratings. The total line lengths for 132, 66 and $33 \mathrm{kV}$ circuits are 180,78 and $325 \mathrm{~km}$, respectively. Half-hourly P and Q monitoring data was made available for 7 (out of 9) BSPs and 31 (out of 39) primary substations.

Planning data (e.g., network reinforcements) provided by NP for 2012 and 2013 is used to first produce a network modelled in OpenDSS [13] from the low voltage side of the GSP transformer $(132 \mathrm{kV})$ downstream to the low voltage side of primary substations. Operational data have also been considered in the network models. More specifically, the actual voltage targets and tapping time delays of on-load tap changers of BSP and primary transformers have been used. To carry out the daily time-series simulations required by steps 1 to 4 of the proposed methodology the critical weeks identified in [8] are adopted (low Q/P ratios at GSPs across Great Britain).

Following steps 1 and 2, Fig. 6 shows the P profiles at the GSP and 3 BSPs obtained from time-series simulations during $28^{\text {th }}$ May 2012 using the allocated load/generation profiles as well as monitoring data. The average $P_{\text {mismatch }}$ at the GSP and all BSPs ranges from 0.1 to $0.2 \%$. These small mismatches demonstrate that the network model, as currently used by the DNO, is, as expected, adequate for active power studies.

The aim of step 3 of Stage 2 of the proposed approach is to match monitoring Q data with simulation results at the GSP.

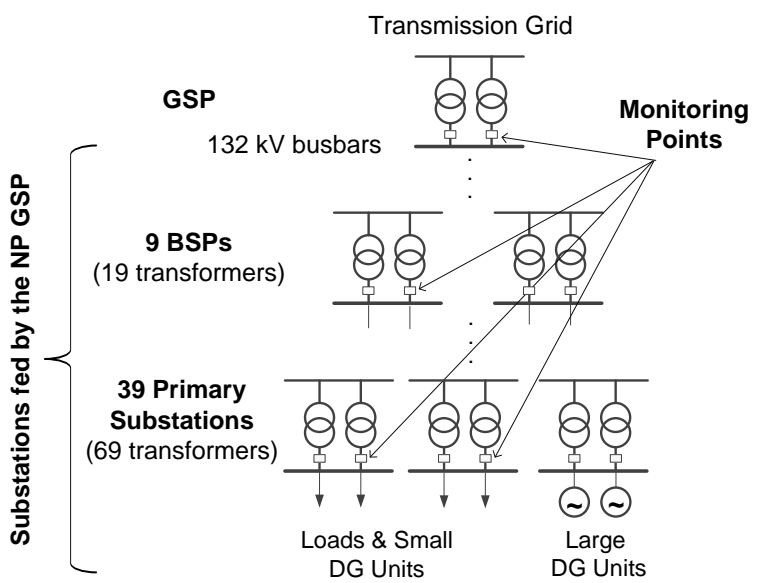

Fig. 5. Substations fed by the studied critical NP GSP.

TABLE I - BSP SUBSTATIONS FED BY THE NP GSP

\begin{tabular}{c|c|c}
\hline Substation & Transformer & Rating (MVA) \\
\hline BSP\#1 & $2 \times(132 / 66 \mathrm{kV})$ & $2 \times 150$ \\
\hline BSP\#2 to \#4 & $2 \times(132 / 33 \mathrm{kV})$ & $2 \times 90$ \\
\hline BSP\#5 & $2 \times(132 / 33 \mathrm{kV})$ & $2 \times 60$ \\
\hline BSP\#6 & $1 \times(132 / 33 \mathrm{kV})$ & $1 \times 90$ \\
\hline BSP\#7 & $2 \times(132 / 25 \mathrm{kV})$ & $2 \times 18$ \\
\hline BSP\#8 & $2 \times(132 / 11 \mathrm{kV})$ & $2 \times 30$ \\
\hline BSP\#9 & $2 \times(132 / 6.6 \mathrm{kV})$ & $2 \times 30$ \\
\hline
\end{tabular}

TABLE II - PRIMARY SUBSTATIONS FED BY THE NP GSP

\begin{tabular}{c|c}
\hline Transformer & Rating (MVA) \\
\hline $1 \times(66 / 33 \mathrm{kV})$ & $1 \times 32$ \\
\hline $18 \times(66 / 11 \mathrm{kV})$ & $10 \times 32,4 \times 30,2 \times 24,2 \times 18.75$ \\
\hline $44 \times(33 / 11 \mathrm{kV})$ & $2 \times 33,6 \times 32,20 \times 24,8 \times 18.75$, \\
$2 \times 15,4 \times 14,1 \times 10,1 \times 7.5$ \\
\hline $2 \times(33 / 6.6 \mathrm{kV})$ & $2 \times 15$ \\
\hline $2 \times(20 / 11 \mathrm{kV})$ & $2 \times 10$ \\
\hline
\end{tabular}

As also shown in Fig. 6, in this case, the Q profiles present a significant mismatch. The average $Q_{\text {mismatch }}$ at the GSP and all BSPs ranges from 25 to $108 \%$. This and similar studies [12] highlight the challenges faced by DNOs in creating network models particularly for reactive power studies.

Although the monitoring data at the GSP shows many instances with an aggregated capacitive behavior (injecting reactive power to transmission), particularly from midnight to $6 \mathrm{am}$, it is noteworthy that at all time instants the sum of the individual reactive power demands of all primary substations is inductive (i.e., absorbing reactive power). Consequently, in this case, it is evident that the interactions of the primary substation demand (during a critical day) with the upstream network result in significant $\mathrm{Q}$ gains.

It should be noted that in the UK it is common for DG units to operate close to unity power factor and that DNOs do not typically use reactive power compensation. Thus, Q gains are likely to mainly occur due to the susceptances of the lines between primary substations and the GSP. This effect, however, is not seen in the simulations and, therefore, the corresponding values in the original DNO network data need to be further investigated. Indeed, neither line susceptances for 66 and $33 \mathrm{kV}$ circuits, nor the proportion of overhead lines and cables were available for the studied network.

Following step 3, line susceptances are updated by finding an equivalent cable penetration that results in the best $Q_{\text {mismatch }}$. Typical per unit length susceptances of overhead 


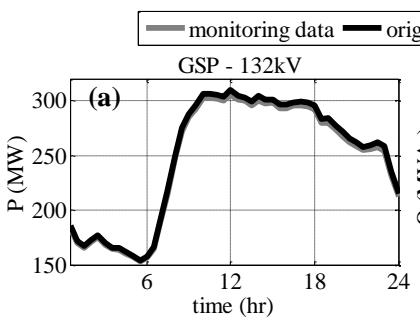

original model with allocated loads
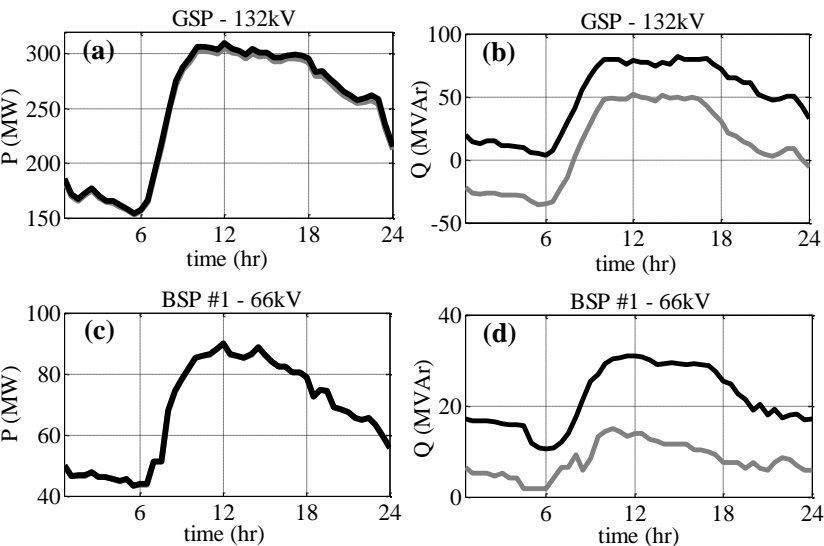

BSP \#1 - 66kV

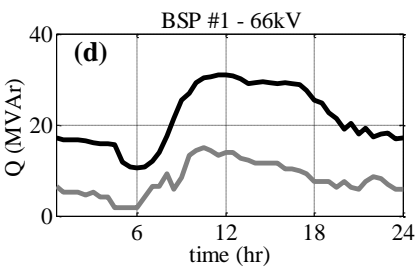

Fig. 6. P and Q monitoring and simulation profiles at the NP GSP and BSP \# for $28^{\text {th }}$ May 2012 (critical day).
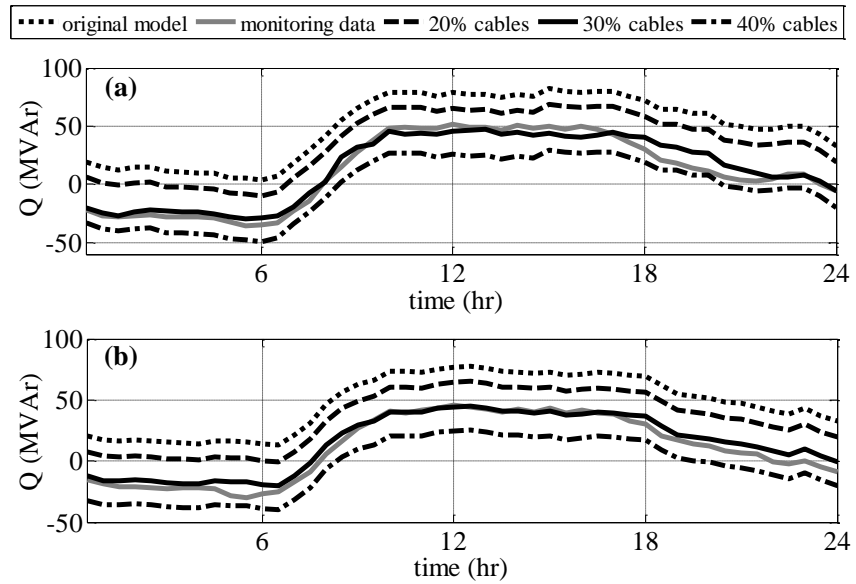

Fig. 7. Q profiles at the NP GSP: a) $28^{\text {th }}$ May 2012 and b) $18^{\text {th }}$ June 2013.

lines and XLPE insulated cables are adopted for every voltage level [14]. Fig. 7a shows the daily Q demand for the critical day considering 20, 30 and $40 \%$ of cable penetration. The best match with the monitoring data is found with $30 \%$, i.e., $30 \%$ of the length of the lines in each voltage level are modelled with typical susceptances of XLPE cables. The reminder $70 \%$ adopt susceptances of overhead lines.

Finally, in step 4, the adequacy of considering line susceptances equivalent of a $30 \%$ of cable penetration, and thus, the corresponding Q gains, is verified comparing daily simulations with monitoring data for different days (both in summer and winter) and years. Fig. 7b shows daily Q profiles for a critical day in 2013 and adopting the three cable penetrations previously investigated. The results verify that with $30 \%$ cable penetration, the $\mathrm{Q}$ gains in the new network would be able to better mimic the actual behavior of the GSP during periods of minimum $\mathrm{P}$ demand. Thus, this validated network model is hereafter considered for all the remaining analyses.

\section{Stage 3: Network Planning}

From 2009 to 2014, network reinforcements upstream of primary substations reported by DNOs (e.g., UKPN Long Term Development Statement [15]) have been found to be limited in critical GSPs, and in general, across Great Britain
[9]. Similarly, scheduled reinforcements for 2015-2020 were also negligible, particularly in terms of the adoption of cables. Consequently, based on the available DNO information, there is no trend regarding network changes.

In terms of DG, PV generation is the fastest growing technology in the UK with more than $11 \mathrm{GW}$ of installed capacity [17], most of which is connected downstream of primary substations. According to the Future Energy Scenarios (FES) produced by the UK TSO [11], the total PV installed capacity is expected to increase yearly by around 0.75 to $1.5 \%$ of the aggregated nationwide UK peak load in 2013 $(60.5 \mathrm{GW})$, i.e., from approximately 0.45 to $0.9 \mathrm{GW}$ per annum. This trend is adopted for the scenarios in Stage 4.

\section{Effects of Cable Penetration, DG and Demand Trends}

In this section, the effects from significant changes in cable penetration, DG and demand trends on $\mathrm{Q}$ demand at T-D interfaces during minimum load are quantified individually considering the validated network model of the studied critical NP GSP (i.e., using an equivalent $30 \%$ cable penetration). This analysis helps illustrating the impact that each of these factors can have on the decline of Q demand.

\section{1) Cable Penetration}

Significant replacements of 132,66 , and $33 \mathrm{kV}$ overhead lines with cables are investigated considering the critical day of $18^{\text {th }}$ June 2013 (minimum Q demand of -20Mvar at $6.30 \mathrm{am})$. All combinations from 40 to $100 \%$ of cable penetration (using 20\% steps) across all voltage levels are taken into account.

Fig. 8 shows the minimum Q demand at the GSP for each of the 64 combinations of cable penetrations during the day. While a $100 \%$ cable penetration in 66 and $33 \mathrm{kV}$ can lead to -43 Mvar (115\% more var exports to transmission), an extra $20 \%$ cable penetration in $132 \mathrm{kV}$ results in -50 Mvar $(150 \%$ more var exports). Although from 2009 to 2014 DNOs in Great Britain have carried out limited (or no) network changes in $132 \mathrm{kV}$ circuits, these findings demonstrate that even a relatively small increase in cable penetration at this voltage level could significantly increase var exports to transmission.

\section{2) PV Penetration}

To assess the effects of high PV penetrations on $\mathrm{Q}$ demand at the NP GSP, PV penetrations -from 10 to 50\%- across all primary substations are considered with respect to the corresponding peak $\mathrm{P}$ demand in 2013, i.e., from 48 to $240 \mathrm{MW}$ of total PV installed capacity. Half-hourly PV generation profiles are derived from [18] considering the irradiance for the studied location/date. Following DG practice in the UK, PV generation is considered to operate at unity power factor.

Fig. 9 shows the daily $\mathrm{P}$ and $\mathrm{Q}$ profiles at the examined GSP for different PV penetration levels. Clearly, even with high PV penetrations, the $\mathrm{Q}$ demand until $7 \mathrm{am}$ is not significantly affected (from -20 to -22.1 Mvar) due to the limited irradiance early in the morning. From 8 am to $6 \mathrm{pm}$, however, when PV generation is large, the impact on both $\mathrm{P}$ and Q demands is noticeable. 


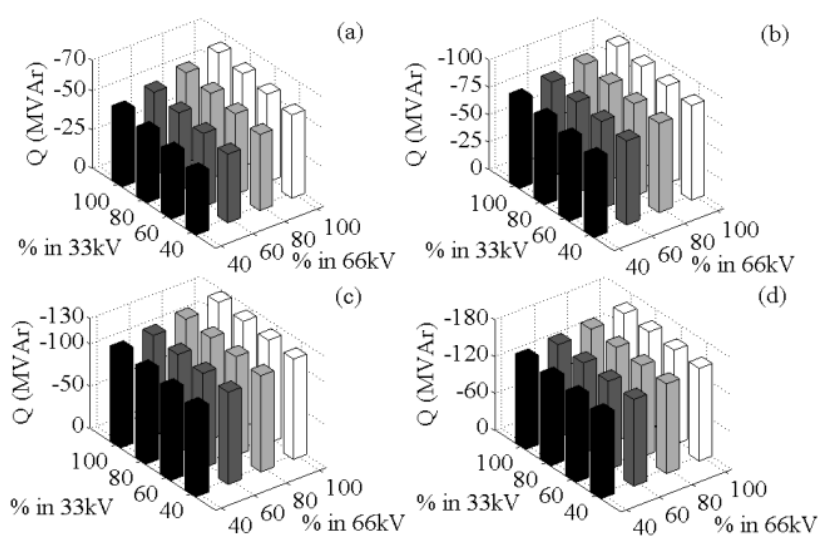

Fig. 8. Q profiles at the GSP: a) $28^{\text {th }}$ May 2012 and b) $18^{\text {th }}$ June 2013.
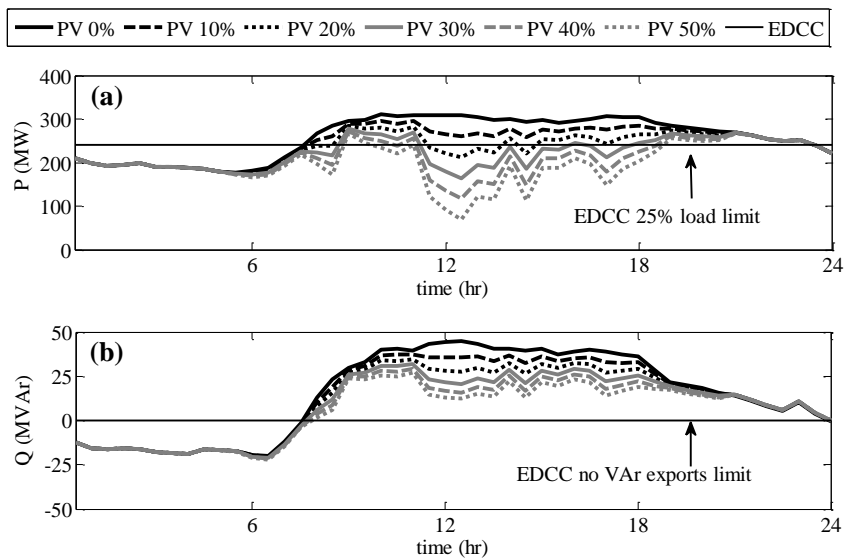

Fig. 9. Demand at the examined GSP for different PV penetration levels: a) daily $P$ profile and $b$ ) daily $Q$ profile.

Assuming the suggested values from the EDCC [4] (likely to be applicable only to new networks), with small PV penetrations (up to 10\%), the DNO might be required to decrease var exports from $11.30 \mathrm{pm}$ to $7.30 \mathrm{am}$ (periods with less than $25 \%$ of the GSP capacity, i.e., $240 \mathrm{MW}$ ). However, with larger volumes of $\mathrm{PV}$, the resulting net $\mathrm{P}$ demand lies below the suggested EDCC limit for many more hours during the day. Although here no var exports would need to be managed outside the original period, this highlights that DNOs and the TSO could potentially face significant challenges throughout the day when in addition to high PV penetrations other factors occur (e.g., more cables).

\section{3) Primary Demand Trends}

Using 2012 and 2013 monitoring data for the NP GSP, the yearly linear declines of aggregated $\mathrm{P}$ and $\mathrm{Q}$ primary demand during periods of minimum load for May to July days were found to be equal to circa 2 and 9\%, respectively [14]. This means that the minimum aggregated primary demand of 30.7 Mvar ( $18^{\text {th }}$ June 2013 , year 0$)$ will decrease by $2.8 \mathrm{MVar}$ yearly if this trend continues. This and two other trends for $\mathrm{P}$ and $\mathrm{Q}$ demand $( \pm 50 \%$ of the identified linear decline) are presented in Fig. 10a for a horizon of 5 years. To quantify the corresponding effects on the Q demand at the GSP, these P and $\mathrm{Q}$ trends are used in simulations using the validated network model. Fig. 10b shows the results.

The Q demand at the GSP exhibits a yearly decrease of 4.2Mvar for the existing trend, i.e., 50\% more than the aggregated decrease of primaries (2.8Mvar). This, which also
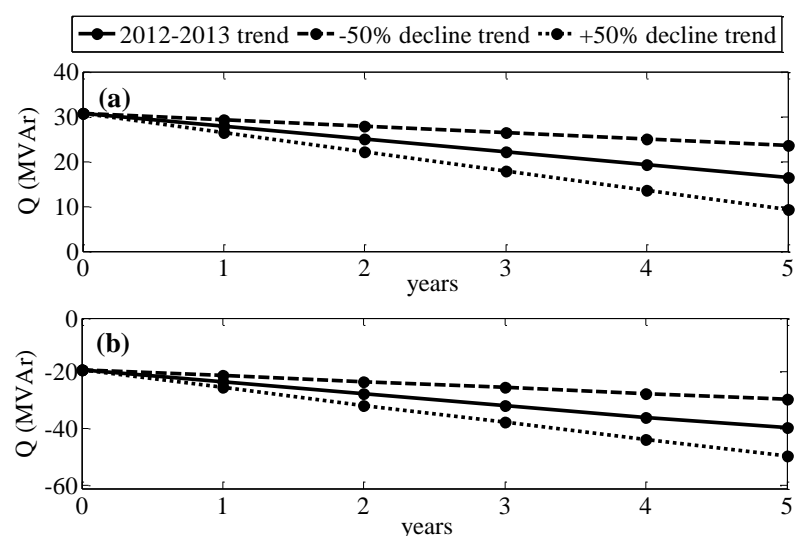

Fig. 10. Future trends for: a) aggregated $Q$ demand at primaries, and b) $Q$ demand at the NP GSP.

\begin{tabular}{c|c|c|c}
\multicolumn{4}{c}{ TABLE III - TREND-BASED SCENARIOS } \\
\cline { 2 - 4 } Scenario & $\begin{array}{c}\text { Yrimary Demand } \\
\text { Trends }\end{array}$ & $\begin{array}{c}\text { PV } \\
\text { Penetration }\end{array}$ & $\begin{array}{c}\text { Network } \\
\text { Changes }\end{array}$ \\
\hline Existing Trends & $\begin{array}{c}\text { Existing: -2\% P } \\
\text { and -9\% Q }\end{array}$ & $+1.00 \%$ & - \\
\hline Go Green & $\begin{array}{c}\text { Existing: -2\% P } \\
\text { and -9\% Q }\end{array}$ & $+1.50 \%$ & - \\
\hline Effective Loads & $\begin{array}{c}+50 \%:-3 \% \mathrm{P} \text { and } \\
-13.5 \% \mathrm{Q}\end{array}$ & $+1.00 \%$ & - \\
\hline Slow Progression & $\begin{array}{c}-25 \%:-1.5 \% \mathrm{P} \\
\text { and -6.75\% Q }\end{array}$ & $+0.75 \%$ & - \\
\hline Fast Progression & $\begin{array}{c}+50 \%:-3 \% \mathrm{P} \text { and } \\
-13.5 \% \mathrm{Q}\end{array}$ & $+1.50 \%$ & $\begin{array}{c}+5 \% \text { of } \\
33 \mathrm{kV} \text { cables }\end{array}$ \\
\hline
\end{tabular}

fast progression
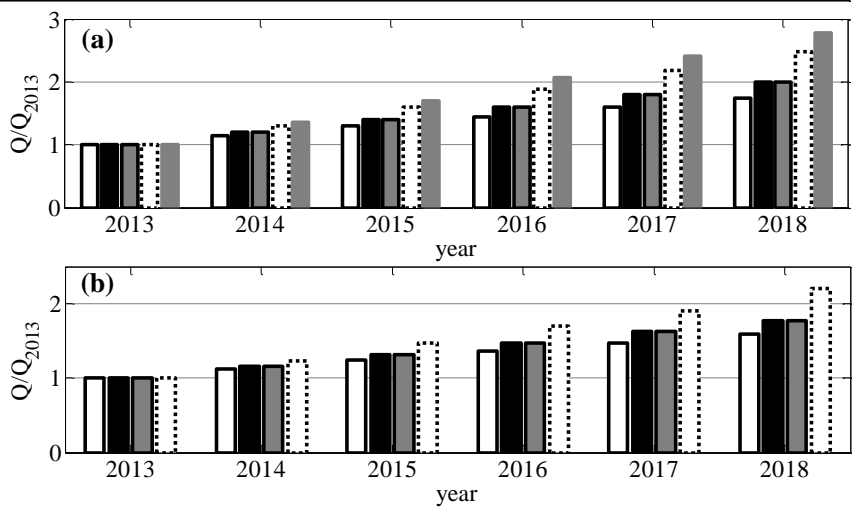

Fig. 11. Future $\mathrm{Q} / \mathrm{Q}_{2013}$ ratio considering the five scenarios for a) the NP GSP and, b) Great Britain (based on 5 critical GSPs).

applies to the other two trends, is due to the Q gains of 132 to $33 \mathrm{kV}$ being boosted by lower levels of $\mathrm{P}$ demand (also declining). Thus, if the identified 2012-2013 demand trend at primary substations continues, it can lead to double $\mathrm{Q}$ exports at the GSP from the original 2013 level in only 5 years.

\section{Future REACtive Power DEMAND IN GREAT BRITAIN - STAGE 4}

The trends adopted by each of the five scenarios of Stage 4 of the proposed methodology (Fig. 2) can be defined taking into account the identified historic primary demand trends (Stage 1) and the UK TSO and DNO network planning information (Stage 3). For the former, 2 and $9 \%$ annual decline of $\mathrm{P}$ and $\mathrm{Q}$ demand, respectively, were identified for the 
studied network and therefore considered in the Existing Trends scenario (business as usual). For the latter, 0.75 and $1.5 \%$ annual increase in PV installations are used for the Slow Progression and Go Green scenarios, respectively; aligned with the FES [11].

The values used to modify these trends according to the rationale of each scenario are presented in Table III. It should be noted that these values are adopted to ensure a wide yet plausible spectrum of future Q demand at the GSP. Since no historic trend was identified for distribution network changes, only the Fast Progression scenario adopts a cable penetration trend of $5 \%$ for $33 \mathrm{kV}$ circuits (which can be considered a challenging pace in the UK).

Fig. 11a shows the future $Q / \mathrm{Q}_{2013}$ ratios for each of the five scenarios specified in Table III. According to the most optimistic scenario, Slow Progression, a 75\% increase in Q exports to transmission is expected after 5 years, i.e., from $\mathrm{Q}_{2013}=-20 \mathrm{Mvar}$ to $\mathrm{Q}_{2018}=-35 \mathrm{Mvar}$. On the other hand, the worst case scenario, Fast Progression, reaches a much more onerous $178 \%$ increase, i.e., -55.6Mvar. A comparison between the Existing Trends and Go Green scenarios demonstrate that higher PV penetrations in the latter have a limited effect on Q exports (during early summer mornings PV generation is limited). Conversely, the cable penetrations makes the Fast Progression scenario export 30\% more Q compared to the Effective Loads scenario by 2018.

From a TSO perspective, if similar trends are identified in more GSPs across different regions or nationwide, the ability to maintain statutory voltage levels during periods of minimum load would be deteriorated. To illustrate this, 4 more critical GSPs (ENWL, SSE, UKPN and WPD) are first analyzed individually. The corresponding Q demand per GSP per year is then aggregated (including the NP GSP) and compared to the 2013 value, which corresponds to var exports. Fig. 11b presents the resulting future $\mathrm{Q} / \mathrm{Q}_{2013}$ ratios. The Fast Progression scenario is not included since the UKPN GSP is fully underground (100\% cables, London area), and the initial cable penetrations of WPD and SSE GSPs could not be determined due to limited availability of primary $\mathrm{P}$ and $\mathrm{Q}$ monitoring data.

Considering the same 5 years horizon, the optimistic Slow Progression and pessimistic Effective Loads scenarios lead to 59 and $121 \%$ increases in $\mathrm{Q}$ exports to transmission, respectively. Although this range is lower than that found for the NP GSP, given that it considers a variety of critical GSPs, it is still significant. Indeed, if similar trends were to be found in most GSPs, this suggests that T-D interfaces across Britain could face in the short-term almost double the $\mathrm{Q}$ exports during periods of minimum load. This also demonstrates that to produce a more accurate regional or national assessment multiple GSPs must be considered.

\section{ECONOMIC ASSESSMENT USING SHUNT REACTORS}

The findings presented so far highlight the urgent need to adopt transmission and/or distribution based solutions to tackle the fast decline in $\mathrm{Q}$ demand during minimum load not
TABLE IV - ECONOMIC ASSESSMENT USING SHUNT REACTORS

\begin{tabular}{l|c|c|c|c}
\hline Shunt Reactors & $\begin{array}{c}\text { Existing } \\
\text { Trend }\end{array}$ & Go Green & $\begin{array}{c}\text { Effective } \\
\text { Loads }\end{array}$ & $\begin{array}{c}\text { Slow } \\
\text { Progression }\end{array}$ \\
\hline Rating (Mvar) & 5,254 & 5,256 & 6,556 & 4,724 \\
\hline $\begin{array}{l}\text { Cost (million } £ \text { ) } \\
\text { Lower Band }\end{array}$ & 131.36 & 131.41 & 163.89 & 118.11 \\
\hline $\begin{array}{l}\text { Cost (million } £ \text { ) } \\
\text { Upper Band }\end{array}$ & 236.45 & 236.53 & 295.01 & 212.59 \\
\hline
\end{tabular}

only to comply with potential future requirements (e.g., EDCC in the European context) but most importantly to ensure transmission voltages are kept within statutory limits. This, however, has to be done adopting cost-effective measures.

This section presents an economic assessment considering the installation of shunt reactors at T-D interfaces as a potential solution with readily available technology. Shunt reactors are considered to cost from $£ 25,000$ (lower band) to $£ 45,000$ (higher band) per Mvar and to be located at GSPs so as to meet a potential zero var requirement, i.e., matching the $\mathrm{Q}$ exports during minimum load.

Table IV presents the total cost of adopting shunt reactors for the top 10 critical GSPs per DNO, i.e. total of 60 critical GSPs across Great Britain [9] considering the nationwide trends of Fig. 11b. The aggregated peak demand of these GSPs was $20.41 \mathrm{GW}$ in 2013 (a third of the approximately 61GW peak demand across all 336 GSPs in Great Britain).

The total investment for all the top 60 critical GSPs ranges from $£ 118$ to $£ 213$ million for the Slow Progression scenario to mitigate more than $4.7 \mathrm{Gvar}$ of exports. The volume of shunt reactors required for the worst case, Effective Loads, exceeds 6.5Gvars and requires an investment ranging from £164 to $£ 295$ million. The amount of investment, however, is not evenly distributed across DNOs due to the different sizes and reactive power exchanges of GSPs [9].

Although the above findings suggest a significant level of investment, in practice, both TSOs and DNOs must investigate solutions that do not involve the installation of new assets. This is discussed in the following section.

\section{Discussion ON SOLUTIONS USING EXISTING AsSETS}

This section discusses three potential solutions that could prove cost effective and implementable in the short term as they use existing assets in distribution networks.

- Voltage management during critical periods: By reducing operating voltages during critical periods across different voltage levels, DNOs could significantly reduce Q gains. Its implementation would require the use of new coordinated settings (e.g., voltage targets) for all the corresponding substations during specific (critical) times. The extent of the benefits will depend on the voltage reduction that could in practice be achieved.

- Tap staggering: By forcing the equal opposite displacement of tap positions in parallel distribution transformers, DNOs could prompt the absorption of vars. This phenomenon, which occurs due to the resulting circulating current, has been recently investigated and trialed in the UK industrial project CLASS [20]. Initial findings suggest that this 
approach can be more cost effective than shunt reactors [21]. Its implementation, however, requires new control devices at each substation. The extent of the benefits will depend on the number and capacities of the substations involved.

- DG power factor: In many countries small-to-medium scale DG units are required to have reactive power capabilities (e.g., 0.95 leading/lagging in the UK). Therefore, there is an opportunity to exploit the absorption of vars by adopting fixed or time-based (critical periods) settings. This, however, requires imposing these settings onto DG operators or the creation of incentives (e.g., as done in Spain for voltage management purposes [19]). The extent of the benefits will depend on the DG technologies and capacities present in the network.

\section{DisCUSSION ON DEMAND CHANGES BELOW PRIMARY SUBSTATIONS}

The observed historical decline in both $\mathrm{P}$ and $\mathrm{Q}$ demand seen at primary substations across Great Britain during periods of minimum load has been identified in this work as one of the key factors affecting the decline of the overall $\mathrm{Q}$ demand at $\mathrm{T}$ $\mathrm{D}$ interfaces. This section discusses efficiency measures and the use of cables when connecting distributed generation downstream primary substations - both aspects likely to have influenced the corresponding aggregated demand.

In the last decade the European Union has introduced a number of requirements to increase the efficiency of domestic appliances, from washing machines to lighting [22]. In the UK, where $20 \%$ of houses use electric heating, incentives have also been created to encourage better home insulation [24]. These efficiency-related measures have not only led to a more than $3 \%$ reduction of electricity demand by domestic customers in the UK from 2011 to 2015 [23] but it is also likely to have significantly reduced reactive power demand given the technological advances in domestic appliances (e.g., use of power electronics).

Although, as demonstrated in section V-D, PV generation has a limited effect on primary substation $\mathrm{P}$ demand during periods of minimum load, the cables used in many cases to connect PV farms (medium-scale installations) can significantly affect $\mathrm{Q}$ demand. Indeed, a number of PV farms in the UK have been connected via long 11 and $6.6 \mathrm{kV}$ underground cables to primary substations [23]. Q demand at these substations during periods of minimum load (e.g., early morning hours) is expected to be reduced due to the $\mathrm{Q}$ gains from these cables given that PV generation will be minimum. Although a similar effect might be seen with wind farms, in the UK those connections mostly occur at higher voltages.

While in the UK, and in most countries around the world, is not currently possible to quantify the extent to which factors below primary substations influence the declining trend in $\mathrm{Q}$ demand, the ongoing deployment of smart meters and further (and more advanced) monitoring infrastructure across substations is likely to help TSOs and DNOs in such a task.

\section{CONClusions}

Transmission System Operators (TSOs) face substantial challenges in managing voltages due to the declining reactive power demand during periods of minimum load. To estimate the extent of this decline, a scenario-based methodology is proposed to identify future trends of reactive power demand at transmission-distribution (T-D) interfaces using historical monitoring and network data from distribution operators.

The acute declining trend of reactive power demand seen in the last decade by the TSO in Great Britain as well as real, large distribution networks were thoroughly investigated. It was found that existing demand trends downstream of primary substations and the associated interactions with networks at higher voltage levels are driving the overall decline of reactive power at T-D interfaces. Scenarios considering the existing demand trends at primary substations indicated that T-D interfaces across Great Britain are likely to experience in 5 years almost double $\mathrm{Q}$ exports during periods of minimum load. Although high PV penetrations were found to have limited effects across all scenarios, the resulting net demand is likely to pose challenges throughout the day. Furthermore, it was found that even small cable penetrations upstream of primary substations could lead to large Q exports to transmission. Further work using network and monitoring data from primary substations down to residential customers, which nowadays is challenging due to its extensiveness and limited availability, is required to identify whether other factors (e.g., efficiency measures, interactions with DG) should be incorporated in the scenarios.

Finally, an initial economic assessment using shunt reactors demonstrated that the identification of the reactive power demand trends is crucial for network planners to investigate the cost-effectiveness of potential solutions. Given that this and other similar traditional solutions can have a significant cost, other options (or combinations) using existing assets should be investigated. Voltage management, tap staggering in parallel transformers and adequate power factor settings for DG plants have been discussed as potential distribution-based solutions. Similarly, transmission-based options should also be examined.

The proposed methodology can be used by transmission and distribution network operators worldwide to assess future reactive power exports at their interfaces and coordinate their actions to take mutually beneficial corrective measures.

\section{ACKNOWLEDGMENT}

The authors would like to thank the support provided by the DNOs ENWL, NP, and UKPN, as well as National Grid.

\section{REFERENCES}

[1] National Grid. (2013). National Electricity Transmission System Performance Report 2013-14. [Online]. Available: http://www2.nationalgrid.com/UK/Industry-information/Electricitytransmission-operational-data/Report-explorer/Performance-Reports/

[2] National Grid. (2015). 2015 System Operability Framework, pp. 92-93. [Online]. Available: http://www2.nationalgrid.com/UK/Industryinformation/Future-of-Energy/System-Operability-Framework/ 
[3] National Grid. (2014). 2014 Electricity Ten Year Statement. [Online]. Available: $\quad$ http://www2.nationalgrid.com/UK/Industryinformation/Future-of-Energy/Electricity-Ten-Year-Statement/

[4] ENTSO-E (2012 Dec.). ENTSO-E Network Code on Demand Connection. [Online]. Available: https://www.entsoe.eu/majorprojects/network-code-development/demandconnection/Pages/default.aspx

[5] P. M. S. Carvalho, F. Correia Pedro, L. F. Ferreira, "Distributed Reactive Power Generation Control for Voltage Rise Mitigation in Distribution Networks" IEEE Trans. on Power Systems, vol. 23, no. 2, pp. 766-772, May 2008.

[6] L. F. Ochoa, A. Keane, G. P. Harrison, "Minimizing the Reactive Support for Distributed Generation: Enhanced Passive Operation and Smart Distribution Networks", IEEE Trans. on Power Systems, vol. 26, no. 4, pp. 2134-2142, Nov. 2011.

[7] K. L. Lo, Y. A. Alturki, "Towards reactive power markets. Part 1: reactive power allocation," IEE Proc. - Generation, Transmission and Distribution, vol.153, no.1, pp.59-70, 12 Jan. 2006.

[8] C. G. Kaloudas, L. F. Ochoa, B. Marshall, S. Majithia, "Initial Assessment of Reactive Power Exchanges at UK Grid Supply Points", in Proc. CIRED Workshop 2014, Rome, Jun. 2014.

[9] C. G. Kaloudas, L. F.Ochoa, B. Marshall, S. Majithia. (2015 Aug.). Deliverable 5. Second Year Final Report Stage 2 - REACT Project. [Online].

Available: http://www.smarternetworks.org/Files/REACT_151111105142.pdf

[10] L. L. Grigsby, Electric Power Generation, Transmission and Distribution, 3rd edition, CRC press, FL, USA, 2012.

[11] National Grid. (2014). UK Future Energy Scenarios. [Online]. Available: http://www2.nationalgrid.com/uk/industryinformation/future-of-energy/future-energy-scenarios/

[12] C. G. Kaloudas, L. F.Ochoa, B. Marshall, S. Majithia. (2015, Apr.). Deliverable 4. Second Year Six Month Report - REACT Project. [Online]. http://www.smarternetworks.org/Files/REACT_151111105435.pdf

[13] R. C. Dugan, T. E. McDermott, "An Open Source Platform for Collaborating on Smart Grid Research", in Proc. IEEE PES General Meeting 2011, July 2011.

[14] C. G. Kaloudas, L. F. Ochoa, I. Fletcher, B. Marshall, S. Majithia, "Investigating the Declining Reactive Power Demand of UK Distribution Networks", in IEEE PES General Meeting 2015, Jul. 2015.

[15] UK Power Networks. (2015, Nov.). Long Term Development Statement [Online]. Available: http://www.ukpowernetworks.co.uk/internet/en/about-us/regulatoryinformation/long-term-development-statement.html
[16] MATLAB and Statistics Toolbox Release 2015b, The MathWorks, Inc., Natick, Massachusetts, United States.

[17] Department for Business, Energy and Industrial Strategy (2016, Nov.). Solar Photovoltaics Deployment in the UK. [Online]. Available: https://www.gov.uk/government/statistics/solar-photovoltaicsdeployment

[18] I. Richardson, M. Thomson, D. Infield, and C. Clifford, "Domestic electricity use: A high-resolution energy demand model," Energy Build, vol.42, pp. 1878-1887, Oct. 2010.

[19] Ministerio de Industria Turismo y Comercio, "REAL DECRETO 661/2007, de 25 de mayo, por el que se regula la actividad de producción de energía eléctrica en régimen especial," 2007

[20] Electricity North West Ltd. (2015 Sep). Customer Load Active System Services Second Tier LCN Fund Project Closedown Report. [Online]. Available: $\quad$ http://www.enwl.co.uk/docs/default-source/classdocuments/class-closedown-report.pdf?sfvrsn $=4$

[21] L. Chen, H. Y. Li, S. Cox, K. Bailey, "Ancillary Service for Transmission Systems by Tap Stagger Operation in Distribution Networks", IEEE Trans. on Power Delivery, vol. 31, no. 4, pp. 17011709, Aug. 2016.

[22] European Commission, Ecodesign Legislation (2016, Nov.). [Online]. Available: https://ec.europa.eu/energy/sites/ener/files/documents/list_of_ecodesign _measures.pdf

[23] Department for Business, Energy and Industrial Strategy (2016, Sep.). Electricity: Chapter 5, Digest of United Kingdom Energy Statistics (DUKES). [Online]. Available: https://www.gov.uk/government/statistics/electricity-chapter-5-digestof-united-kingdom-energy-statistics-dukes

[24] Department of Energy and Climate Change (2016, Mar). Household Energy Efficiency National Statistics, Detailed Report 2015. [Online]. Available:

https://www.gov.uk/government/uploads/system/uploads/attachment_da ta/file/508236/Detailed_report_-_HEE_stats_17_Mar_2016_FINAL_pdf 